\title{
Pulmonary gas exchange immediately after birth in spontaneously breathing infants
}

\author{
C Palme-Kilander, R Tunell, Y Chiwei
}

\begin{abstract}
The pulmonary gas exchange (rate of oxygen consumption, $\dot{\mathrm{V}}_{2}$ and rate of carbon dioxide production, $\dot{\mathrm{V}} \mathrm{CO}_{2}$ ), heart rate, and transcutaneously measured oxygen saturation were measured during the first five minutes after birth in healthy newborn infants. Fifteen full term infants who were vaginally delivered, 15 full term infants born by caesarean section, and 10 preterm infants born by caesarean section were studied. $\dot{\mathrm{V}} \mathrm{o}_{2}$ tended to be slightly higher than $\dot{\mathbf{V}} \mathrm{Co}_{2}$ during the first minutes, with a gradual change to a respiratory exchange ratio above $1 \cdot 0 . \dot{V} o_{2}$ and $\dot{V} \mathrm{Co}_{2}$ were significantly higher in vaginally delivered infants than in those born by caesarean section during the second minute after birth, partly due to a higher number of cries/minute. During periods of calm breathing, $\mathrm{Vo}_{2}$ and $\mathbf{V C O}_{2}$ were significantly higher in vaginally delivered infants than in those born by caesarean section, with low gas exchange levels in infants born by caesarean section during the second minute after birth. Decreased ventilation was reflected by a significant drop in oxygen saturation within $30-45$ seconds.
\end{abstract}

(Arch Dis Child 1993;68:6-10)

In order to compare the effects of assisted ventilation in asphyxiated newborn babies with that of healthy babies breathing spontaneously it is necessary to know how ventilation normally varies during very short periods after birth. Studies should be performed in both vaginally delivered neonates and in infants born by caesarean section, and also in both full term and preterm infants. If the total respiratory adaptation to the transition from uterine to extrauterine life is to be studied, the methods should evaluate not only the ventilatory but also the circulatory part of respiratory adaptation. Studies of the pulmonary gas exchange at birth include both of these aspects, but they have been performed in only a very few earlier studies with conflicting results, and not in spontaneously as well as artificially breathing neonates. ${ }^{1}{ }^{2}$ Studies of the oxygen uptake during and immediately after ventilation on an endotracheal tube have also been performed by the use of a closed system. ${ }^{3-5}$

The aim of the present investigation was therefore to study the pulmonary gas exchange - and primarily the rate of carbon dioxide production $\left.\dot{\mathrm{V}} \mathrm{CO}_{2}\right)$ in spontaneously breathing newborn infants delivered vaginally and after elective caesarean section. It was also considered important to study the changes in transcutaneously measured oxygen saturation and in heart rate in connection with changes in ventilation.

\section{Patients and methods}

METHODS

The equipment for recording pulmonary gas exchange, heart rate, and oxygen saturation has been described earlier. ${ }^{6}$ An open system was used to study pulmonary gas exchange (fig 1). The infants could breathe or be ventilated with carbon dioxide free air or a mixture of $50 \%$ nitrogen in oxygen. The mean (SD) detection of carbon dioxide injected into the gas sampling system was $93(6) \%$, and the method has been shown to work during both spontaneous breathing and assisted ventilation. The exhaled and diluted gas was collected in 20 bags in periods of 15 seconds' duration and analysed for volume and gas fractions after the five minute study period.

Heart rate was recorded by the use of pregelled silver chloride electrodes (Medicotest-N-QQ-25) that were applied to the chest and connected to the pulse oximeter. Oxygen saturation was recorded with a Nellcor 200 transmission pulse oximeter, which was applied to the right hand when this could easily be done, or to a foot when application on the right hand was not feasible.

A tape recorder recorded all events, such as cries and other sounds from the baby and from the Apgar timer, as well as comments on the infant's clinical condition, during the five minute study period.

\section{PATIENTS}

\section{Full term infants}

Fifteen full term healthy infants, delivered vaginally in vertex presentation and 15 full term healthy infants, delivered by elective caesarean section, were studied (table 1). The reasons for elective caesarean section were: fetopelvic disproportion $(n=5)$, psychological reasons, and/or previous caesarean section $(n=5)$, breech presentation $(n=4)$, and placenta praevia $(n=1)$. All 30 patients had uneventful deliveries One mother in the vaginal and one in the caesarean group were treated with labetalol for essential hypertension. There were no other complications during pregnancy. 


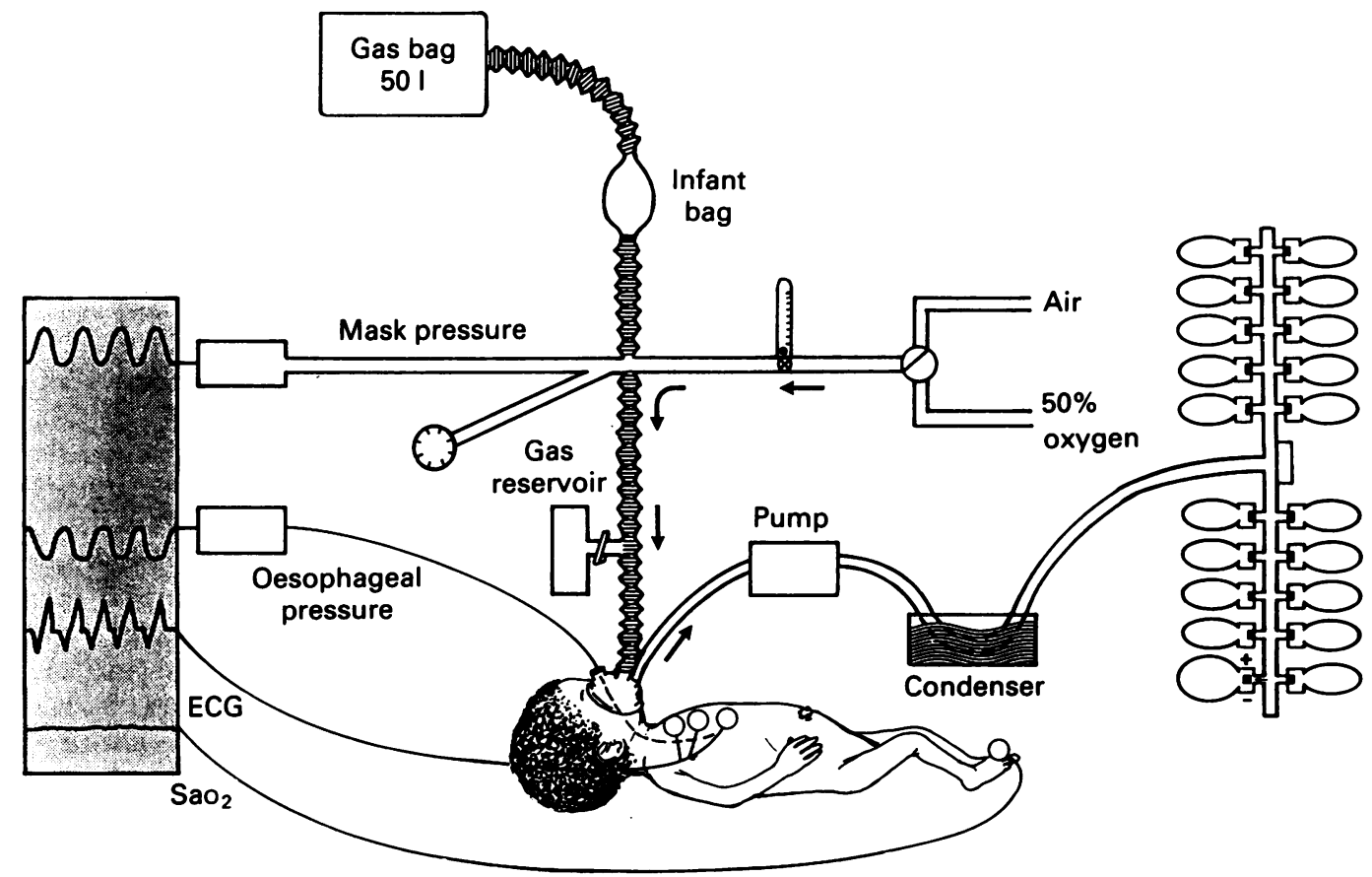

Figure 1 The equipment used for recording pulmonary gas exchange, oxygen saturation ( $\left.\mathrm{SaO}_{2}\right)$, and heart rate (ECG). The connection to the gas reservoir is closed during assisted ventilation and open during spontaneous breathing. The gas sampling bags are shown on the right hand side of the diagram.

Table 1 Data on 30 full term infants. Values are mean (SD) unless otherwise stated

\begin{tabular}{lll}
\hline & Vaginally delivered & Caesarean section \\
\hline Birth weight (g) & $3540(480)$ & $3295(490)$ \\
Gestational age (weeks) & $40 \cdot 2(1 \cdot 0)$ & $38 \cdot 3(1 \cdot 3)$ \\
$\mathrm{pH}$ & $7 \cdot 21(0 \cdot 04)$ & $7 \cdot 27(0 \cdot 06)$ \\
No with pH $<7 \cdot 15$ & $1(7 \cdot 11)$ & $1(7 \cdot 15)$ \\
No with Apgar score $<7$ & 0 & 0 \\
at 1,5 , or 10 minutes & 15 & 15 \\
No without neonatal complications & & 15 \\
\hline
\end{tabular}

Anaesthesia and analgesia-Six vaginally delivered mothers had epidural analgesia, two were given pethidine injections, and five nitrous oxide but not during the 30 minutes preceding delivery. Eleven of the caesarean cases were given epidural anaesthesia. The remaining four had general anaesthesia: $300-400 \mathrm{mg}$ of pentobarbitone and a mixture of $50 \%$ nitrous oxide and $0.75 \%$ enflurane in oxygen.

Preterm infants

Ten preterm infants, born by a caesarean sec-

Table 2 Preterm infants studied during spontaneous breathing

\begin{tabular}{|c|c|c|c|c|c|c|}
\hline $\begin{array}{l}\text { Infant } \\
\text { No }\end{array}$ & $\begin{array}{l}\text { Birth weight } \\
(g)\end{array}$ & $\begin{array}{l}\text { Gestational } \\
\text { age (weeks) }\end{array}$ & $\begin{array}{l}\text { Pregnancy complictions } \\
\text { (medication) }\end{array}$ & $p H$ & $\begin{array}{l}\text { Apgar score } \\
(1-5-10 \mathrm{~min})\end{array}$ & $\begin{array}{l}\text { Neonatal } \\
\text { problems }\end{array}$ \\
\hline 1 & 1380 & 32 & $\begin{array}{l}\text { Toxaemia } \\
\text { (calcium antagonist) }\end{array}$ & $7 \cdot 31$ & $8-9-10$ & - \\
\hline $\begin{array}{l}2 \\
3\end{array}$ & $\begin{array}{l}1540 \\
1600\end{array}$ & $\begin{array}{l}35 \\
36\end{array}$ & $\begin{array}{l}\text { IUGR } \\
\text { Twins }\end{array}$ & $\begin{array}{l}7 \cdot 29 \\
7 \cdot 35\end{array}$ & $\begin{array}{l}9-10-10 \\
8-10-10\end{array}$ & - \\
\hline 4 & 1800 & 34 & $\begin{array}{l}\text { Toxaemia } \\
\text { (labetalol) }\end{array}$ & $7 \cdot 31$ & $8-9-10$ & - \\
\hline 5 & 2065 & 33 & $\begin{array}{l}\text { Toxaemia } \\
\text { placenta praevia } \\
\text { (labetalol+terbutaline) }\end{array}$ & $?$ & $8-10-10$ & $\begin{array}{l}\text { CPAP: } \\
\text { wet } \\
\text { lung }\end{array}$ \\
\hline 6 & 2120 & 33 & PROM+breech & $7 \cdot 23$ & $4-7-10$ & - \\
\hline 7 & 2600 & 36 & $\begin{array}{c}\text { Toxaemia+IUGR } \\
\text { (labetalol) }\end{array}$ & $7 \cdot 29$ & $9-10-10$ & - \\
\hline 8 & 2470 & 33 & PROM+breech & $7 \cdot 27$ & $8-9-10$ & - \\
\hline 9 & 2920 & 36 & Twin, breech & $7 \cdot 32$ & $9-10-10$ & - \\
\hline 10 & 3050 & 35 & $\begin{array}{l}\text { Toxaemia+asthma } \\
\text { (hydralazine) }\end{array}$ & $7 \cdot 32$ & $9-10-10$ & - \\
\hline
\end{tabular}

PROM=premature rupture of membranes

IUGR=intrauterine growth retardation

$\mathrm{CPAP}=$ continuous positive airway pressure. tion, were also studied (table 2). Two of the 10 mothers had premature rupture of the membranes, and one of these mothers was also in labour before caesarean section. Birth weights ranged from 1380 to $3050 \mathrm{~g}$ with a mean of $2120 \mathrm{~g}$, and gestational ages were 32-36 weeks with a mean of 34 weeks.

STATISTICAL METHODS

The data concerning ventilation in subsequent time intervals were compared using analysis of variance. The $t$ test was used to compare single time periods. The data concerning ventilation during periods of calm breathing were compared, using the Wilcoxon rank sum test.

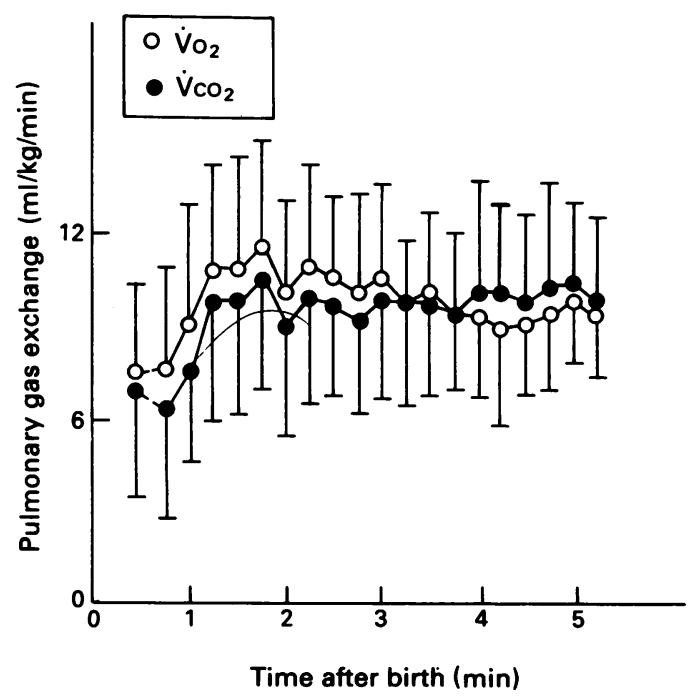

Figure 2 Mean $(S D) \dot{V}_{2}$ and $\dot{V} \mathrm{CO}_{2}$ in vaginally delivered full term infants during the first five minutes after birth. The first recording (between 15 and 30 seconds after birth) is based on findings in 10 infants. All other measurements refer to recordings in all 15 infants. 
The study was approved by the local ethics committee.

\section{Results}

GAS EXCHANGE IN SPONTANEOUSLY

BREATHING TERM INFANTS

The pattern of pulmonary gas exchange in vaginally delivered infants (fig 2 ) during the first five minutes showed great interindividual and intraindividual variations. In the first $0 \cdot 5-1$ minute after birth, both the rate of oxygen consumption $\left(\dot{\mathrm{VO}}_{2}\right)$ and $\dot{\mathrm{V}}_{2}$ were low, the mean $\mathrm{VCO}_{2}$ being $83 \%$ of $\dot{\mathrm{VO}}_{2}$. During the second minute after birth there was an increase in gas exchange to $\mathrm{VCO}_{2} 9 \cdot 7$ $\mathrm{ml} / \mathrm{kg} / \mathrm{min}$ and $\dot{\mathrm{V}}_{2} 10.7 \mathrm{ml} / \mathrm{kg} / \mathrm{min}$, and these values remained mainly unchanged during the next three minutes. The discrepancy

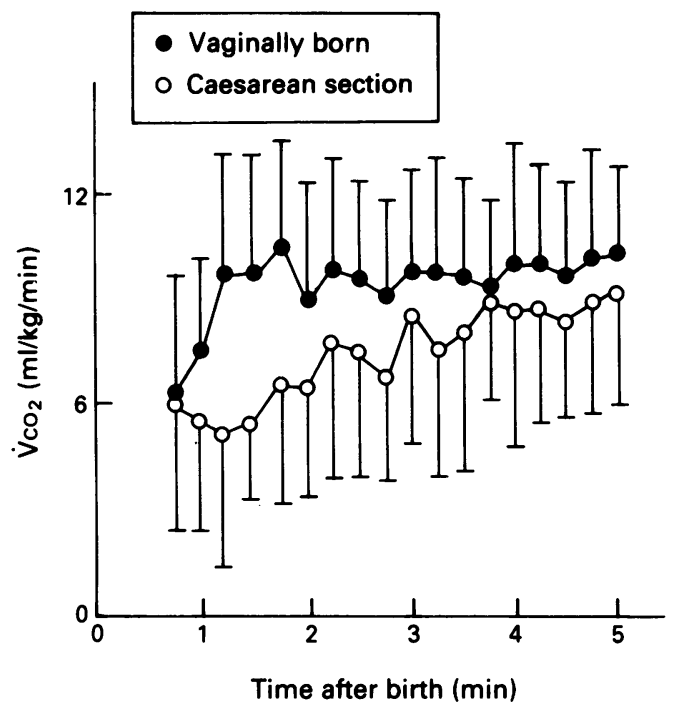

Figure $3 \dot{V} \dot{\mathrm{CO}}{ }_{2}$ in full term vaginally borm and 15 full term infants delivered by caesarean section during the first five minutes after birth. Vaginally delivered infants have a higher $\dot{V} \mathrm{CO}$ than do section infants during the second minute after birth $(p<0.05)$.

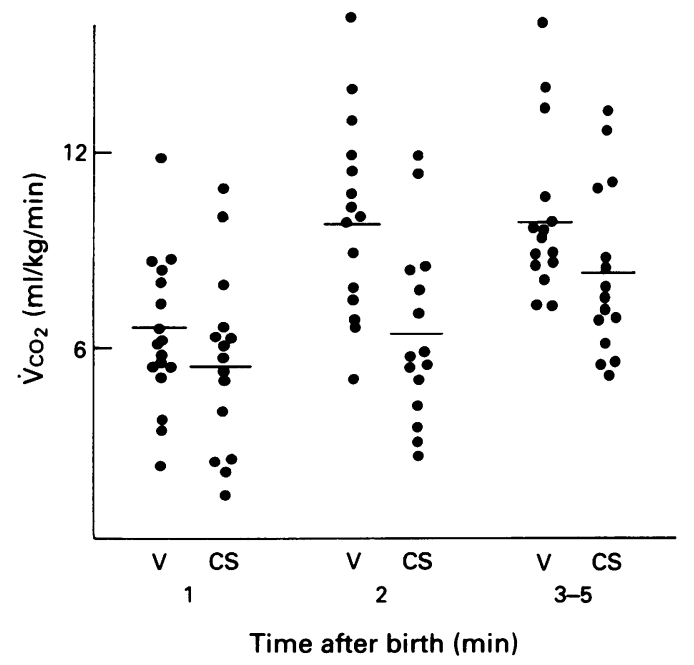

Figure $4 \quad \dot{V} \mathrm{CO}_{2}$ full term infants vaginally delivered $(\mathrm{V})$ and born by caesarean section (CS) during periods of active crying during the second half of the 1st minute, the 2 nd minute, and the $3 \mathrm{rd}-5$ th minutes after birth. $\dot{\mathrm{C}} \mathrm{CO}$ was significantly higher in vaginally delivered infants in the second minute ( $p>0.05)$. Mean $\dot{\mathrm{V}} \mathrm{CO}_{2}$ is indicated by the bar. between $\dot{\mathrm{V}} \mathrm{O}_{2}$ and $\dot{\mathrm{V}} \mathrm{CO}_{2}$ disappeared during the first three minutes, resulting in a respiratory exchange ratio above 1.0 after four minutes.

In the infants delivered by caesarean section (fig 3), gas exchange was not different from that in vaginally delivered infants during the second half of the first minute, but it remained low during the second minute in contrast to those born vaginally $(p<0.05)$ and increased slowly. in the next three minutes. The relation of $\dot{\mathrm{V}} \mathrm{O}_{2}$ to $\dot{\mathrm{V}} \mathrm{CO}_{2}$ was the same as in the vaginally delivered infants with $\mathrm{VCO}_{2} 6 \cdot 2$ and $\mathrm{VO}_{2} 7 \cdot 2 \mathrm{ml} / \mathrm{kg} / \mathrm{min}$ in the second minute with a gradual disappearance of the difference in the following minutes.

All full term infants were studied during periods of active crying. The pattern of oxygen uptake and carbon dioxide elimination during these active periods is the same as during the entire sampling periods, with a more rapid increase during the second minute after birth in vaginally delivered than in caesarean section neonates (fig 4). Periods of quiet breathing occurred in five of the vaginally delivered and eight of the caesarean section babies during the second minute, and in nine and 11 of the babies during the three to five minutes after birth. These values showed a greater discrepancy as the median $\dot{\mathrm{V}} \mathrm{CO}_{2}$ in caesarean section babies was only $2 \cdot 1$ $\mathrm{ml} / \mathrm{kg} / \mathrm{min}$ during the second minute after birth, rising to $6 \mathrm{ml} / \mathrm{kg} / \mathrm{min}$ at three to five minutes (fig 5).

\section{GAS EXCHANGE IN SPONTANEOUSLY} BREATHING PRETERM NEONATES

$\dot{\mathrm{V}} \mathrm{O}_{2}$ was measured only in two preterm infants. The remaining seven were initially given $50 \%$ oxygen instead of air. A gradual increase in $\mathrm{VCO}_{2}$ was also noted in preterm infants, as can be seen in fig 6 . In the infants born by caesarean section, there was no difference between the gas exchange in the full term and preterm neonates. There was no

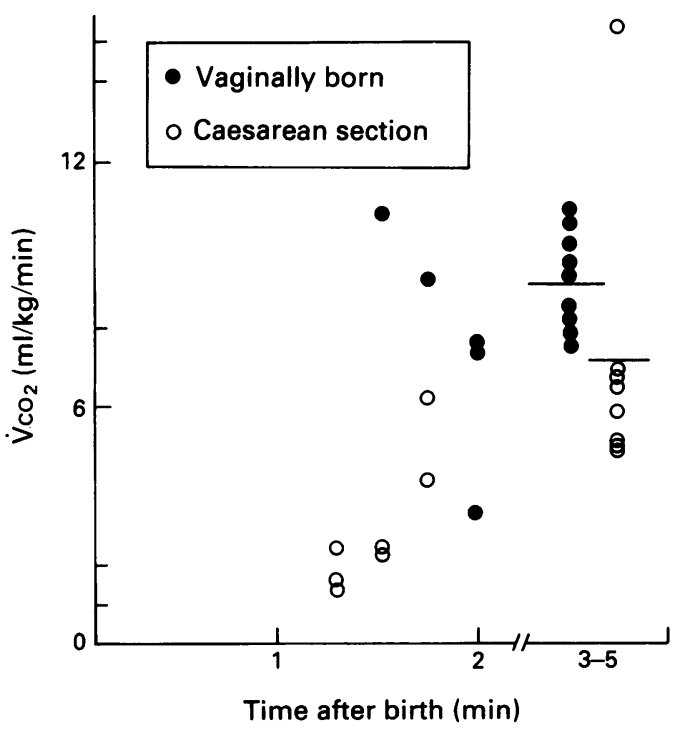

Figure $5 \dot{\mathrm{V}} \mathrm{CO}_{2}$ during periods of calm breathing is higher in full term infants vaginally delivered than in those born by caesarean section during the 2 nd minute $(p<0.01)$ and during the $3 r d-5$ th minutes $(p<0.05)$. Individual values and means are shown. 


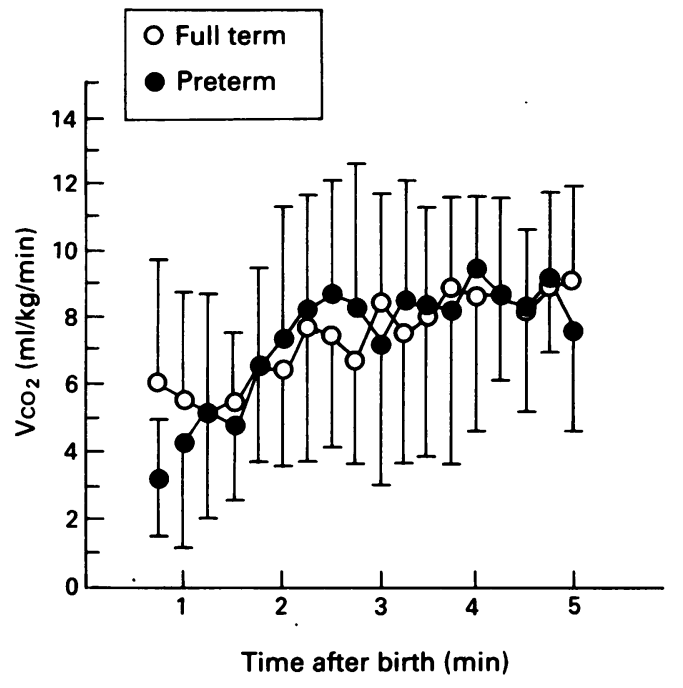

Figure $6 \quad \dot{V} \mathrm{CO}_{2}$ in 15 full term infants born by caesarean section and 10 preterm infants delivered by caesarean section during the first five minutes after birth. There are no significant differences.

relation between birth weight or gestational age and gas exchange.

\section{RELATION OF HEART RATE AND OXYGEN}

SATURATION TO GAS EXCHANGE IN NEWBORN INFANTS.

Heart rates varied widely. In full term babies there was no infant who had a heart rate below 130 beats/minute when carbon dioxide elimination exceeded $7 \mathrm{ml} / \mathrm{kg} / \mathrm{min}$. Oxygen saturation was measured in the right hand when this could easily be done (four vaginal deliveries and eight caesarean section infants) or in a foot (11 vaginal and three caesarean section infants). In two cases, when the measurements were performed simultaneously in the right hand and in a foot, the values in the foot were $10-15 \%$ lower than those in the right hand.

A transient decrease in $\dot{\mathrm{V}} \mathrm{O}_{2}$ and $\dot{\mathrm{V}} \mathrm{CO}_{2}$ to less than $4 \mathrm{ml} / \mathrm{kg} / \mathrm{min}$ was reflected by a $20-30 \%$ decrease in oxygen saturation with a delay of 30-40 seconds in nine of 10 infants. In one baby there were no changes in oxygen saturation, despite changes in ventilation. Periods with decreased ventilation were not reflected by a decrease in heart rate.

\section{Discussion}

Studies, performed over 30 years ago, have shown that the respiratory adaptation of the healthy newborn baby is very rapid and complete within one to two minutes after birth. Roentgenograms demonstrated that the lungs were fully aerated at the end of the first breath $^{7}$ and that most neonates-but not all, and less often the more preterm ones-had a considerable amount of residual air in the lungs after the first expiration. ${ }^{8}$ Early studies on the mechanics of breathing indicated that the majority of healthy full term neonates had already formed some functional residual capacity in the lung after the first breath. ${ }^{9}$
There is reason to believe that-particularly in caesarean section neonates and in preterm infants-immediately after birth aeration of the lungs and pulmonary gas exchange are deficient because of residual lung fluid. Studies in human neonates have shown that the functional residual capacity is formed less efficiently in caesarean section than in vaginally delivered infants, ${ }^{10}$ and that infants delivered by a caesarean section preceded by labour constituted an intermediate group who established a functional residual capacity earlier than those born without prior labour. ${ }^{11}$ Infants studied within the first 30 minutes after birth had lower compliance, lower tidal volume and lower catecholamine concentrations if they were born by elective caesarean section than by vaginal delivery. ${ }^{12}$

Studies of pulmonary gas exchange during spontaneous breathing at very short time intervals directly after birth, as in the present study, have not previously been presented. The period of five minutes was chosen because ventilatory adaptation by the healthy normal newborn is usually completed within this period.

The present study has shown that during the second half of the first minute after birth $\dot{\mathrm{VO}}_{2}$ and $\dot{\mathrm{VCO}}_{2}$ are almost equally low in vaginally delivered and caesarean section infants. In the second minute, however, the vaginally delivered infants have a high and efficient gas exchange which remains high even when the infants do not cry. This initial increase takes place with virtually no increase in the number of cries/minute. In infants delivered by elective caesarean section the increase in $\mathrm{VO}_{2}$ and $\dot{\mathrm{VCO}}_{2}$ is slower, but after two minutes not significantly different from that of vaginally delivered infants during periods of active crying. The lower $\dot{\mathrm{V}} \mathrm{CO}_{2}$ in caesarean section born neonates depends partly on a smaller number of cries/minute during the second minute after birth than in vaginally born infants.

During calm breathing there is an obvious difference in gas exchange during the entire five minute period: the $\mathrm{VCO}_{2}$ and $\dot{\mathrm{VO}}_{2}$ of vaginally delivered infants remain high with a median $\mathrm{VCO}_{2}$ of $7.6 \mathrm{ml} / \mathrm{kg} / \mathrm{min}$ during the second minute after birth, but the $\dot{\mathrm{V}} \mathrm{CO}_{2}$ and $\dot{\mathrm{VO}}_{2}$ of caesarean section neonates decline to significantly lower levels with a median $\dot{\mathrm{V}} \mathrm{CO}_{2}$ of $2 \cdot 1 \mathrm{ml} / \mathrm{kg} / \mathrm{min}$. This is considerably lower than the basic metabolic rate of $5-6 \mathrm{ml} / \mathrm{kg} / \mathrm{min}$. A poor aeration, with decreased functional residual capacity ${ }^{11}$ and hypoventilation, are probably responsible for this.

Most of the studied preterm infants were breathing oxygen instead of air, and thus only $\dot{\mathrm{V}} \mathrm{CO}_{2}$ could be measured in this group. $\dot{\mathrm{V}} \mathrm{CO}_{2}$ in preterm infants delivered by caesarean section was not different from full term infants born in the same way. The preterm infants studied had a mean birth weight of $2120 \mathrm{~g}$, and studies in smaller babies might have given other results.

When levels of $\dot{\mathrm{V}} \mathrm{CO}_{2}$ in spontaneously breathing infants are compared with levels achieved in ventilated asphyxic infants, it is therefore important to consider the mode of 
delivery. Preterm infants should be able to reach the same levels of $\mathrm{VCO}_{2}$ as term infants provided the mode of delivery is the same and that the gestational age is at least 33 weeks. For both groups of term infants, $\mathrm{VO}_{2}$ slightly exceeded $\mathrm{VCO}_{2}$ during the first minutes after birth. The initially high uptake of oxygen is needed to increase the oxygen stores of the blood. During the five minute period $\dot{V}_{\mathrm{CO}_{2}}$ increased relative to $\dot{\mathrm{VO}}_{2}$ simultaneously with a known increase in acidosis in the circulating blood. ${ }^{13}$ This leads to a respiratory exchange ratio over 1.0 towards the end of the five minute period, which has been reported elsewhere. ${ }^{1}$

To increase the oxygen stores of the blood approximately $7 \mathrm{ml}$ oxygen $/ \mathrm{kg}$ is needed in the absence of shunts. ${ }^{14}$ With the high levels of oxygen uptake that are recorded the time needed to saturate the haemoglobin with oxygen should be very short - not more than two minutes in most infants. The slow increase in oxygen saturation, which we have recorded in a foot compared with in the right hand, depends largely on a high degree of right to left shunting through the ductus arteriosus. This is consistent with other studies, where the oxygen tension in the blood increased rapidly during the first minutes after birth when samples were drawn preductally from the aortic arch, compared with a slow increase when blood from the iliac artery was analysed, ${ }^{13}$ and to a study where oxygen saturation, measured in the right hand, increased more rapidly and was uniformly higher than when recordings were performed from a foot. ${ }^{15}$ During vigorous crying, the rise in oxygen saturation was slower also in the right hand, which was ascribed to increased shunting during crying. A $50 \%$ decrease in $\mathrm{VCO}_{2}$ to less than $4 \mathrm{ml} / \mathrm{kg} / \mathrm{min}$ was accompanied by a decrease in oxygen saturation of $20-30 \%$ with a delay of 30-45 seconds.

Changes in heart rate did not reflect changes in pulmonary gas exchange. The most obvious reason for this is that most infants cried vigorously again within less than one minute after periods of calm breathing. The heart rate did not fall instantaneously during calm breathing with a low pulmonary gas exchange.
The results of this study are in agreement with earlier findings that pulmonary adaptation to extrauterine life is completed rapidly in healthy, vaginally delivered infants, whereas those who are born by caesarean section have a slower adaptation. Infants born by caesarean section depend to a great extent on vigorous crying during the first minutes after birth in order to have an adequate gas exchange.

The study was supported by grants from the AGA Medical Research Foundation, the General Maternity Hospital's Memorial Fund and Karolinska Institute, Sweden

1 Tunnell R, Copher D, Persson B. The pulmonary gas exchange and blood gas changes in connection with birth In: Stetson JB, Swyer PR, eds. Current concepts of neoantal intensive care. St Louis: Warren Green, 1974:89-106.

2 Pribylova $\mathrm{H}$, Znamenacek $\mathrm{K}$. The effect of body temperature on the level of carbohydrate metabolites and oxygen
consumption in the newborn. Pediatrics 1966;37:743.

3 Ditchburn RK, Hull D, Segall MM. Oxygen uptake during and after positive pressure ventilation for the resuscitation of asphyxiated newborn infants. Lancet 1966;ii:1096-9.

4 Hey E, Kelly J. Gaseous exchange during endotracheal ventilation for asphyxia at birth. Fournal of Obstetrics and Gynaecology of the British Commonwealth 1968;75:414-24.

5 Hull $D$. Lung expansion and ventilation during resuscitation of asphyxiated newborn infants. $\mathcal{F}$ Pediatr 1969;75: $47-58$

6 Palme-Kilander C, Tunell R. Equipment for recording pulmonary gas exchange immediately after birth during spontaneous breathing and assisted ventilation. Med Biol Eng Comput (in press).

7 Fawcett J, Lind J, Wegelius C. The first breath. A preliminary communication describing some methods of investigation of the first breath of a baby and the results gation of the first breath of a baby and the results 123):5-17

8 Lind $\mathrm{J}$. Initiation of breathing in the newborn infant. fournal of the Irish Medical Association 1962;50:88-93.

9 Karlberg P, Cherry RB, Escardó FE. Respiratory studies in newborn infants. II. Pulmonary ventilation and mechanics of breathing in the first minutes of life, including the onset of respiration. Acta Paediatrica 1962;51:121-36.

10 Vyas $\mathrm{H}$, Milner AD, Hopkin IE. Intrathoracic pressure and volume changes during the spontaneous onset of respiration in babies born by caesarean section and by vaginal delivery. F Pediatr 1981;99:787-91.

11 Vyas $H$, Milner AD, Hopkin IE, Falconer AD. Role of labour in the establishment of functional residual capacity at birth. Arch Dis Child 1983;58:512-7.

12 Faxelius G, Hägnevik K, Lagercrantz H, Lundell B, Irestedt $\mathrm{L}$. Catecholamine surge and lung function after delivery. Arch Dis Child 1983;52:262-6.

13 Engström L, Karlberg P, Rooth G, Tunell R. The onset of respiration: a study of respiration and changes in blood gases and acid-base balance. New York: Association for the Aid of Crippled Children, 1966.

14 Jones JG, Holland BM, Veale KEA, et al. 'Available oxygen', a realistic expression of the ability of the blood to supply oxygen to tissues. Scandinavian foumal of Haematology 1979;22:77.

15 Meier-Stauss P, Bucher HU, Hurliman R, König V, Huch R. Pulse oximetry used for documenting oxygen saturation and right-to-left shunting immediately after birth Eur f Pediatr 1990;149:851-5. 